\title{
Escores de cloaca e de crista e morfometria testicular em galos de matriz pesada com 71 semanas de idade e três categorias de peso corporal
}

\author{
[Cloaca and comb scores and testicular morphometry in broiler breeder roosters at 71 weeks \\ of age and three body weight categories]
}

C.A. Rezende, N.C. Baião, L.E.A. Ruiz, P.R. Xavier, A.P. Marques Júnior

Escola de Veterinária - Universidade Federal de Minas Gerais - Belo Horizonte, MG

\begin{abstract}
RESUMO
Em galos de matriz pesada, o peso dos testículos se associa positivamente com a produção diária de espermatozoides e com a fertilidade. Contudo, os testículos de aves se localizam na cavidade abdominal, não sendo acessíveis para exame andrológico como os testículos de mamíferos. A avaliação reprodutiva de galos de matriz pesada é subjetiva e se baseia em características como peso corporal (PC), qualidade de pés e pernas e morfologia de cloaca e crista. Estudos que validem o potencial de associação dessas características fenotípicas com parâmetros da morfometria testicular são raros, principalmente quando se consideram galos de matriz pesada manejados em lotes comerciais. Escores de cloaca e de crista e parâmetros da morfometria testicular foram avaliados em galos Cobb 500 Slow adultos das categorias de PC leve $(\leq 4,300 \mathrm{~kg})$, médio (entre 4,300 e $5,250 \mathrm{~kg})$ e pesado $(\geq 5,250 \mathrm{~kg})$. O coeficiente de variação para PC foi de $12 \%$. Os galos da categoria de PC pesado apresentaram testículos mais pesados e maiores escores de cloaca e de crista do que os galos da categoria de PC leve. Não houve diferença estatística entre as categorias de PC, considerando-se índice gonadossomático, porcentagens de túbulo seminífero e de tecido intersticial, diâmetro de túbulo seminífero e altura de epitélio seminífero. Correlação positiva, moderada e significativa foi observada entre peso de testículo e características de PC, escores de cloaca e de crista, diâmetro de túbulo seminífero e altura de epitélio seminífero. Um dos seis galos da categoria de PC leve avaliados quanto à histologia de testículo apresentou atrofia testicular. Em galos Cobb 500 Slow, conclui-se que o PC influencia o peso e a qualidade histológica de testículos e que os escores de cloaca e de crista podem ser utilizados com potencial moderado de predição para identificar galos com baixo peso de testículos.
\end{abstract}

Palavras-chave: galo, cloaca, crista, testículos, peso

\begin{abstract}
In broiler breeder roosters the weight of the testes is positively associated with daily sperm production and fertility. However, the avian testes are located in the abdominal cavity, not being accessible for reproductive evaluation as mammalian testes. The reproductive evaluation of broiler breeder roosters is subjective and is based on characteristics such as body weight $(B W)$, quality of feet and legs and morphology of cloaca and comb. Studies that validate the potential of associating these phenotype characteristics with testicular morphometric parameters are rare, especially when broiler breeder roosters of commercial flocks are considered. Cloaca and comb scores and testicular morphometric parameters were evaluated in adult Cobb 500 Slow roosters with low ( $\leq 4.300 \mathrm{~kg}$ ), medium (between 4.300 and $5.250 \mathrm{~kg}$ ) and high $(\geq 5.250 \mathrm{~kg}) \mathrm{BW}$ categories. The coefficient of variation for $B W$ was $12 \%$. The high $B W$ roosters have heavier testes and higher cloaca and comb scores than the low BW roosters. There was no statistical difference between the $B W$ categories in gonadosomatic index, percentage of seminiferous tubule and interstitial tissue, diameter of the seminiferous tubule and height of the seminiferous epithelium. Testis weight is positive, moderate and significantly correlated with BW, cloaca and comb scores, diameter of seminiferous tubule and height of seminiferous epithelium. One of six low BW roosters evaluated for histology of the testis had testicular atrophy. We conclude that in Cobb 500 Slow roosters BW influences the weight and histological quality of the testes. Besides this, cloaca and comb scores can be used with moderate prediction potential to identify roosters with underweight testes.
\end{abstract}

Keywords: rooster, cloaca, comb, testes, weight

Recebido em 31 de outubro de 2012

Aceito em 7 de novembro de 2013

E-mail:candraderezende@yahoo.com.br 


\section{INTRODUÇÃO}

O consumo de carne de frango no mundo aumentou cerca de $12 \%$ nos últimos cinco anos como reflexo do aumento da demanda por proteína animal, principalmente na China, no Brasil e na Índia. Estima-se que esses países sejam responsáveis por $85 \%$ do crescimento previsto na produção global de carne de frango em 2013 (USDA, 2012). Entretanto, o setor de produção de pintos de corte tem enfrentado dificuldades em responder à maior demanda do mercado consumidor com aumentos de produtividade.

No manejo de matrizes pesadas, há desafios consideráveis ao aumento da produção de pintos por ave alojada. Um deles é manter alta persistência de fêmeas em postura após pico de produção de ovos, que ocorre em torno de 30 semanas de idade. Outro é manter bons resultados de fertilidade após 45 semanas de idade. Redução da fertilidade de galos após os concomitantes picos de produção de ovos e de fertilidade ocorre devido à diminuição dos estímulos neuroendócrinos à função testicular, ao comprometimento do processo de espermiação e à redução das concentrações de espermatozoides no ejaculado (Rosenstrauch et al., 1994; Weil et al., 1996; Rosenstrauch et al., 1998; Weil et al., 1999). Com o aumento da idade de galos, observa-se também menor libido e menor frequência de cópulas bem-sucedidas (Hocking e Bernard, 1997; 2000).

Estratégias de manejo se relacionam com bons resultados de fertilidade em lotes mais velhos de matrizes pesadas. Uma delas é controlar o peso corporal para que os galos obtenham ganho de peso positivo, moderado e uniforme durante toda a vida. Hocking e Bernard (2000) mostraram que a fertilidade de galos $C o b b 500$ não foi afetada pela idade quando o ganho de peso corporal foi devidamente controlado. Outra estratégia de manejo é o spiking, um procedimento pelo qual se introduzem galos jovens em lote de aves mais velhas, antes que a fertilidade comece a cair, buscando prolongar bons resultados de fertilidade e eclodibilidade no lote. Recomendase descarte de galos aparentemente improdutivos, sendo aqueles com sobrepeso corporal os mais indicados (Cobb-vantress, 2008).
Em galos de matriz pesada, o peso dos testículos se associa positivamente com a produção diária de espermatozoides e com a fertilidade (Hocking, 1990; Kirby et al., 1998). Contudo, os testículos de aves se localizam na cavidade abdominal, não sendo acessíveis para exame andrológico como os testículos de mamíferos (Amann, 1999). Em lotes comerciais de matrizes pesadas, não é de viabilidade prática e econômica avaliar parâmetros seminais ou a fertilidade de indivíduos. A avaliação reprodutiva de galos é subjetiva. Sobrepeso corporal e problemas de pés ou de pernas são fenótipos sugestivos de impotência sexual, enquanto baixo peso corporal, crista de baixa qualidade e cloaca pequena, pálida e seca são fenótipos sugestivos de subfertilidade. Estudos que validem o potencial de associação dessas características fenotípicas sugestivas de subfertilidade com parâmetros da morfometria testicular são escassos, principalmente em galos de matriz pesada manejados em condições normais de uma criação comercial. $\mathrm{O}$ presente trabalho avaliou peso corporal, morfologia de cloaca e de crista e parâmetros da morfometria testicular de galos de matriz pesada de um lote comercial, no qual as interações sociais entre as aves ocorreram livremente.

\section{MATERIAL E MÉTODOS}

O projeto foi aprovado pela Comissão de Ética no Uso de Animais (Ceua) da UFMG (Protocolo $n^{\circ} .68$ / 2012).

Pintos machos e fêmeas de um dia de idade da linhagem Cobb 500 Slow (empenamento lento) foram alojados separadamente em um galpão comercial situado no município de Pitangui (MG). Eles receberam alimentação ad libitum até a quarta semana de idade. Na quinta semana de idade, iniciou-se o manejo de restrição alimentar para controle de peso corporal. Da quinta à $10^{\mathrm{a}}$ semana de idade, o programa de restrição alimentar utilizado foi o 5x2 (skip-two-days; a quantidade máxima e restrita de ração que a ave pode comer por semana é fornecida em cinco dias, e em dois dias não consecutivos a ave fica sem receber alimento); da $11^{\mathrm{a}}$ à $15^{\mathrm{a}}$ semana de idade, utilizou-se o programa de restrição alimentar 6x1 (Skip-one-day; a quantidade máxima e restrita de ração que a ave pode comer por semana é fornecida em seis dias, e em um dia a ave fica sem receber alimento); e a partir 
da $16^{\mathrm{a}}$ semana, o manejo de restrição alimentar foi diário (fornecimento restrito de ração diariamente, num curto período de fornecimento). Na fase de produção, o sistema de alimentação foi separado por sexo, ou seja, comedouro automático tipo calha, com grade, para as fêmeas, e comedouro manual suspenso tipo calha para os machos. As dietas variaram em composição, de acordo com os requerimentos nutricionais das fêmeas ao longo da idade e foram as mesmas para machos e fêmeas, segundo manejo de rotina da granja. A quantidade de alimento fornecida seguiu a tabela da linhagem com ajustes semanais (mais ou menos ração) feitos de acordo com o peso corporal médio das aves, visando obter o ganho de peso padrão da linhagem. Água de qualidade foi fornecida ad libitum. Até o quinto dia de idade, os pintos receberam 23 horas de luz por dia. Entre o sexto dia e a $21^{\text {a }}$ semana de idade, eles receberam somente luz natural, e o comprimento do dia foi decrescente. $\mathrm{Na} 22^{\mathrm{a}}$ semana de idade, passaram a receber 14 horas contínuas de luz por dia, sendo que o período de luz natural foi complementado e antecedido por luz artificial. Machos e fêmeas foram acasalados com 22 semanas de idade, na proporção de $10,5 \%$ de machos, que, ao longo da fase de produção, diminuiu para $8,5 \%$, devido à mortalidade e aos descartes. Na produção, as temperaturas mínima e máxima no galpão variaram de 7,8 a $19,9^{\circ} \mathrm{C}$ e de 20,1 a $36,0^{\circ} \mathrm{C}$, respectivamente. Quando os galos chegaram à idade de 71 semanas, as categorias de peso corporal foram estabelecidas com base na média de peso corporal de uma amostra aleatória de $5 \%$ $(n=90)$ de galos do lote. Os valores de peso corporal $10 \%$ acima e $10 \%$ abaixo da média foram considerados como limítrofes entre as categorias pesado/médio e médio/leve, respectivamente (ver resultados). Um dia depois, galos das categorias de peso corporal leve $(n=32)$, médio $(n=60)$ e pesado $(n=28)$ foram obtidos do lote, identificados e inspecionados por avaliador treinado quanto à morfologia de cloaca e de crista. Os escores de cloaca e de crista foram determinados subjetivamente, por inspeção visual de tamanho, coloração e lubrificação da cloaca e de tamanho, coloração, turgidez e aspecto da pele da crista (Tab.1).

Tabela 1. Características avaliadas para determinação dos escores de cloaca e de crista

\begin{tabular}{|c|c|c|c|}
\hline $\begin{array}{c}\text { Características avaliadas na } \\
\text { cloaca }\end{array}$ & $\begin{array}{l}\text { Escore de } \\
\text { cloaca }\end{array}$ & $\begin{array}{c}\text { Características avaliadas na } \\
\text { crista }\end{array}$ & $\begin{array}{l}\text { Escore de } \\
\text { crista }\end{array}$ \\
\hline $\begin{array}{l}\text { Tamanho } \\
\text { Pequena } \\
\text { Média } \\
\text { Grande }\end{array}$ & $\begin{array}{l}1 \\
2 \\
3\end{array}$ & $\begin{array}{l}\text { Crista subdesenvolvida e/ou } \\
\text { pálida e/ou murcha com pele } \\
\text { rugosa }\end{array}$ & 1 \\
\hline $\begin{array}{l}\text { Coloração } \\
\text { Pálida } \\
\text { Vermelho-clara } \\
\text { Vermelho-intensa }\end{array}$ & $\begin{array}{l}1 \\
2 \\
3\end{array}$ & $\begin{array}{l}\text { Crista média ou grande, } \\
\text { vermelho- clara, túrgida e com } \\
\text { pele lisa }\end{array}$ & 2 \\
\hline $\begin{array}{l}\text { Lubrificação } \\
\text { Seca } \\
\text { Úmida }\end{array}$ & $\begin{array}{l}1 \\
2\end{array}$ & $\begin{array}{l}\text { Crista grande, vermelho-intensa, } \\
\text { túrgida e com pele lisa }\end{array}$ & 3 \\
\hline & $3-8 *$ & $\begin{array}{l}\text { Crista muito grande, vermelho- } \\
\text { intensa, túrgida e com pele lisa }\end{array}$ & 4 \\
\hline
\end{tabular}

*O escore é dado pelo somatório dos pontos obtidos na avaliação de tamanho, coloração e lubrificação de cloaca, podendo ser no mínimo 3 e no máximo 8 .

Os galos foram abatidos em abatedouro, segundo as normas de abate humanitário, que consiste em insensibilização e sangria. No processo de evisceração, os testículos foram prontamente individualizados, removidos, pesados em balança analítica digital e acondicionados em solução de glutaraldeído $4 \%$ em tampão fosfato $0,05 \mathrm{M}$. O testículo direito de seis galos, obtidos aleatoriamente de cada categoria de peso corporal, foi destinado à histologia. Os testículos foram acondicionados inteiros, sem cortes e sem remoção da albugínea, em solução de glutaraldeído $4 \%$ em tampão fosfato $0,05 \mathrm{M}$ por duas horas. Apesar de a albugínea diminuir a penetração do fixador, ela mantém a organização estrutural do parênquima testicular, muito friável nos galos domésticos, para que este seja préfixado e se mantenha estruturado ao ser 
seccionado posteriormente. Um corte sagital e cortes transversais completos foram efetuados ao longo dos testículos e os fragmentos foram novamente acondicionados em solução de glutaraldeído $4 \%$ em tampão fosfato $0,05 \mathrm{M}$ para melhor penetração do fixador. Após fixação completa do tecido, três pequenos cortes foram obtidos, um na região central do parênquima e um em cada polo (cranial e caudal) dos testículos, tomando-se o cuidado para selecionar as porções mais próximas à superfície, onde a preservação tecidual é melhor. Os cortes foram desidratados em séries crescentes de álcool etílico $(70 \%$ por 30 minutos; $80 \%$ por 30 minutos; $90 \%$ por 30 minutos e $95 \%$ por duas vezes de 30 minutos) e embebidos em metacrilato. Após endurecimento da resina, secções de $4 \mu \mathrm{m}$ de espessura foram obtidas em micrótomo eletrônico para confecção de lâminas histológicas. Elas foram coradas com azul de toluidina e analisadas por meio de microscópio de luz.

Para o cálculo do índice gonadossomático, o somatório do peso dos testículos foi dividido pelo peso corporal (ambos em gramas) e o resultado foi multiplicado por 100. A proporção volumétrica de túbulos seminíferos e de tecido intersticial foi mensurada utilizando-se uma ocular integradora de 441 interseções acoplada à ocular do microscópio. Para esse propósito, 10 campos foram aleatoriamente analisados em aumento de $200 x$, totalizando 4.410 pontos contados por ave. O somatório dos pontos incidentes nos túbulos seminíferos e o somatório dos pontos incidentes no tecido intersticial foram divididos por 4.410 e multiplicados por 100 para o cálculo da proporção volumétrica. $\mathrm{O}$ diâmetro de túbulo seminífero e a altura de epitélio seminífero foram obtidos com régua de $1 \mathrm{~cm}$, com 100 divisões, acoplada à ocular do microscópio. Para tanto, 20 secções transversais de túbulos seminíferos, mais arredondadas possíveis, foram analisadas em aumento de 200x. Duas medidas perpendiculares do diâmetro de túbulo seminífero foram obtidas em cada secção transversal. O menor diâmetro foi considerado o diâmetro verdadeiro. Duas medidas da altura de epitélio seminífero foram realizadas tangenciando o menor diâmetro, e a média aritmética foi calculada.

O delineamento experimental foi inteiramente ao acaso. As variáveis foram estudadas por estatística descritiva. As variáveis quantitativas de distribuição normal foram submetidas à análise de variância e ao teste de Duncan. Os escores de crista e de cloaca foram submetidos ao teste de Kruskal-Wallis (Statistical..., 1999). O nível de significância foi de 5\%.

\section{RESULTADOS E DISCUSSÃO}

O peso corporal dos galos variou de 3,55 a $6,20 \mathrm{~kg}$, com média de 4,81kg, desvio-padrão de $587 \mathrm{~g}$ e coeficiente de variação (CV) de $12 \%$. As categorias de peso corporal foram definidas como leve $(\leq 4,30 \mathrm{~kg})$, médio (entre 4,30 e $5,25 \mathrm{~kg})$ e pesado $(\geq 5,25 \mathrm{~kg})$.

Os galos da categoria pesado apresentaram maior peso de testículos que os galos da categoria leve $(\mathrm{P} \leq 0,05)$. Não houve diferença estatística significativa no peso de testículos entre os galos das categorias pesado e médio ou entre os galos das categorias médio e leve (Tab. 2). O peso corporal apresentou correlação positiva, moderada e significativa com o peso de testículos (Tab. 3). Não houve diferença significativa no índice gonadossomático dos galos das categorias leve, médio e pesado (Tab. 2 ), indicando que o peso corporal e o peso de testículos variam de forma proporcional.

Tabela 2. Peso dos testículos direito e esquerdo, peso médio dos testículos e índice gonadossomático de galos Cobb 500 Slow com 71 semanas de idade, em função da categoria de peso corporal

\begin{tabular}{ccccc}
\hline $\begin{array}{c}\text { Categoria de peso } \\
\text { corporal }(\mathrm{PC})\end{array}$ & $\begin{array}{c}\text { Peso testículo direito } \\
(\mathrm{g})\end{array}$ & $\begin{array}{c}\text { Peso testículo } \\
\text { esquerdo }(\mathrm{g})\end{array}$ & $\begin{array}{c}\text { Peso médio dos } \\
\text { testículos }(\mathrm{g})\end{array}$ & IGS $(\%)$ \\
\hline Leve & $\mathrm{n}=26$ & $\mathrm{n}=26$ & $\mathrm{n}=25$ & $\mathrm{n}=25$ \\
PC $\leq 4,30 \mathrm{~kg}$ & $7,65 \pm 3,69 \mathrm{~B}$ & $8,02 \pm 4,05 \mathrm{~B}$ & $7,73 \pm 3,87 \mathrm{~B}$ & $0,38 \pm 0,18 \mathrm{~A}$ \\
Médio & $\mathrm{n}=42$ & $\mathrm{n}=36$ & $\mathrm{n}=34$ & $\mathrm{n}=34$ \\
$4,30<\mathrm{PC}<5,25 \mathrm{~kg}$ & $9,47 \pm 3,39 \mathrm{AB}$ & $9,68 \pm 4,29 \mathrm{AB}$ & $9,22 \pm 3,76 \mathrm{AB}$ & $0,38 \pm 0,16 \mathrm{~A}$ \\
Pesado & $\mathrm{n}=19$ & $\mathrm{n}=20$ & $\mathrm{n}=18$ & $\mathrm{n}=18$ \\
PC $\geq 5,25 \mathrm{~kg}$ & $11,01 \pm 2,47 \mathrm{~A}$ & $11,05 \pm 2,47 \mathrm{~A}$ & $11,06 \pm 2,25 \mathrm{~A}$ & $0,40 \pm 0,08 \mathrm{~A}$ \\
\hline
\end{tabular}

Resultados apresentados como média \pm desvio-padrão. Médias e desvios seguidos de letras diferentes na mesma coluna diferem pelo teste de Duncan $(\mathrm{P} \leq 0,05) . \mathrm{n}=$ número de repetições. IGS = índice gonadossomático. 
Escores de cloaca e de crista...

Tabela 3. Correlações de Pearson-Spearman entre peso corporal, escores de crista e de cloaca e parâmetros da morfometria testicular de galos Cobb 500 Slow com 71 semanas de idade

\begin{tabular}{|c|c|c|c|c|c|c|c|c|c|}
\hline & PTd & PTe & IGS & DiaTS & AltES & $\% \mathrm{TS}$ & $\% \mathrm{TI}$ & Ecrista & Ecloaca \\
\hline $\mathrm{PC}$ & $\begin{array}{l}\mathrm{n}=87 \\
\mathrm{r}=0,43^{\mathrm{M}} \\
* * * * *\end{array}$ & $\begin{array}{l}\mathrm{n}=82 \\
\mathrm{r}=0,37^{\mathrm{M}} \\
* * *\end{array}$ & $\begin{array}{l}\mathrm{n}=77 \\
\mathrm{r}=0,12 \\
\mathrm{~ns}\end{array}$ & $\begin{array}{l}\mathrm{n}=18 \\
\mathrm{r}=0,37 \\
\mathrm{~ns}\end{array}$ & $\begin{array}{l}\mathrm{n}=18 \\
\mathrm{r}=0,40 \\
\mathrm{~ns}\end{array}$ & $\begin{array}{l}\mathrm{n}=18 \\
\mathrm{r}=012 \\
\mathrm{~ns}\end{array}$ & $\begin{array}{l}\mathrm{n}=18 \\
\mathrm{r}=-0,13 \\
\mathrm{~ns}\end{array}$ & $\begin{array}{l}\mathrm{n}=120 \\
\mathrm{r}=0,49^{\mathrm{M}} \\
* * * * *\end{array}$ & $\begin{array}{l}\mathrm{n}=120 \\
\mathrm{r}=0,21^{\mathrm{L}} \\
*\end{array}$ \\
\hline PTd & & $\begin{array}{l}\mathrm{n}=77 \\
\mathrm{r}=0,91^{\mathrm{F}} \\
* * * *\end{array}$ & $\begin{array}{l}\mathrm{n}=77 \\
\mathrm{r}=0,91^{\mathrm{F}} \\
* * * * *\end{array}$ & $\begin{array}{l}\mathrm{n}=18 \\
\mathrm{r}=0,65^{\mathrm{M}} \\
* *\end{array}$ & $\begin{array}{l}\mathrm{n}=18 \\
\mathrm{r}=0,55^{\mathrm{M}} \\
*\end{array}$ & $\begin{array}{l}\mathrm{n}=18 \\
\mathrm{r}=0,38\end{array}$ & $\begin{array}{l}\mathrm{n}=18 \\
\mathrm{r}=-0,38\end{array}$ & $\begin{array}{l}\mathrm{n}=87 \\
\mathrm{r}=0,45^{\mathrm{M}} \\
* * * *\end{array}$ & $\begin{array}{l}\mathrm{n}=87 \\
\mathrm{r}=0,36^{\mathrm{M}} \\
* * * *\end{array}$ \\
\hline IGS & & & & $\begin{array}{l}\mathrm{n}=18 \\
\mathrm{r}=0,65^{\mathrm{M}} \\
* *\end{array}$ & $\begin{array}{l}\mathrm{n}=18 \\
\mathrm{r}=0,44 \\
\mathrm{~ns}\end{array}$ & $\begin{array}{l}\mathrm{n}=18 \\
\mathrm{r}=0,52^{\mathrm{M}} \\
* *\end{array}$ & $\begin{array}{l}\mathrm{n}=18 \\
\mathrm{r}=-0,51^{\mathrm{M}} \\
*\end{array}$ & $\begin{array}{l}\mathrm{n}=77 \\
\mathrm{r}=0,31^{\mathrm{M}} \\
* *\end{array}$ & $\begin{array}{l}\mathrm{n}=77 \\
\mathrm{r}=0,33^{\mathrm{M}} \\
* *\end{array}$ \\
\hline DiaTS & & & & & $\begin{array}{l}\mathrm{n}=18 \\
\mathrm{r}=0,91^{\mathrm{F}} \\
* * * *\end{array}$ & $\begin{array}{l}\mathrm{n}=18 \\
\mathrm{r}=0,73^{\mathrm{F}} \\
* * *\end{array}$ & $\begin{array}{l}\mathrm{n}=18 \\
\mathrm{r}=-0,73^{\mathrm{F}} \\
* * *\end{array}$ & $\begin{array}{l}\mathrm{n}=18 \\
\mathrm{r}=0,07 \\
\mathrm{~ns}\end{array}$ & $\begin{array}{l}\mathrm{n}=18 \\
\mathrm{r}=0,20 \\
\mathrm{~ns}\end{array}$ \\
\hline AltES & & & & & & $\begin{array}{l}\mathrm{n}=18 \\
\mathrm{r}=0,67^{\mathrm{M}} \\
* *\end{array}$ & $\begin{array}{l}\mathrm{n}=18 \\
\mathrm{r}=-0,67^{\mathrm{M}} \\
* *\end{array}$ & $\begin{array}{l}n=18 \\
r=-0,002 \\
n s\end{array}$ & $\begin{array}{l}\mathrm{n}=18 \\
\mathrm{r}=0,05 \\
\mathrm{~ns}\end{array}$ \\
\hline$\% \mathrm{TS}$ & & & & & & & $\begin{array}{l}\mathrm{n}=18 \\
\mathrm{r}=-1,0^{\mathrm{F}} \\
* * * *\end{array}$ & $\begin{array}{l}\mathrm{n}=18 \\
\mathrm{r}=-0,19 \\
\mathrm{~ns}\end{array}$ & $\begin{array}{l}\mathrm{n}=18 \\
\mathrm{r}=0,13 \\
\mathrm{~ns}\end{array}$ \\
\hline$\% \mathrm{TI}$ & & & & & & & & $\begin{array}{l}\mathrm{n}=18 \\
\mathrm{r}=0,17 \\
\mathrm{~ns}\end{array}$ & $\begin{array}{l}\mathrm{n}=18 \\
\mathrm{r}=-0,16 \\
\mathrm{~ns}\end{array}$ \\
\hline Ecrista & & & & & & & & & $\begin{array}{l}\mathrm{n}=120 \\
\mathrm{r}=0,27^{\mathrm{L}} \\
* *\end{array}$ \\
\hline
\end{tabular}

Peso corporal (PC). Peso de testículo direito (PTd). Peso de testículo esquerdo (PTe). Índice gonadossomático (IGS). Diâmetro de túbulo seminífero (DiaTS). Altura de epitélio seminífero (AltES). Porcentagem de túbulo seminífero (\%TS). Porcentagem de tecido intersticial (\%TI). Escore de crista (Ecrista). Escore de cloaca (Ecloaca). Número de repetições (n). Coeficiente de correlação (r). Letras sobrescritas indicam correlação leve (L), moderada (M) ou forte (F). Asteriscos indicam que a correlação é significativa e representam o nível de significância $\mathrm{P} \leq 0,05(*), \mathrm{P} \leq 0,01(* *)$, $\mathrm{P} \leq 0,001(* * *)$ e $\mathrm{P} \leq 0,0001(* * * *)$. Associações entre características quantitativas de distribuição normal foram estudadas pela correlação de Pearson. Associações entre os escores de crista e cloaca e destes com as demais características foram estudadas pela correlação de Spearman.

Coeficiente de variação de $12 \%$ para peso corporal em aves de alta padronização genética para crescimento corporal pode ocorrer quando há aves no sistema ganhando peso em detrimento de outras. Os resultados mostraram que os galos da categoria pesado apresentaram testículos mais pesados que os da categoria leve, sinalizando que ganho de peso na fase de produção tem implicações positivas no peso de testículos. Ao trabalhar com galos Cobb 500 mantidos separadamente em boxes com 15 galinhas e que receberam quantidades controladas de alimento no período de 20 a 60 semanas de idade para obter diferenças planejadas no ganho de peso, Hocking (1990) observou que galos com maior ganho de peso no período experimental apresentaram maior peso de testículos ao final das 60 semanas, quando foram eutanasiados. Possivelmente, diferenças na alocação de alimento/galo também ocorrem naturalmente em lotes comerciais, devido às interações sociais galo dominante - galo subordinado.
Não houve diferença estatística entre os pesos dos testículos direito e esquerdo. Dos 18 galos avaliados quanto à histologia de testículo direito, o de menor peso corporal $(3,50 \mathrm{~kg})$ apresentou atrofia testicular $(1 / 18 ; 5,5 \%)$. Nos demais galos, a espermatogênese foi aparentemente normal $(17 / 18 ; 94,5 \%)$ (Fig.1).

O peso médio dos testículos do galo com atrofia testicular foi de $1,9 \mathrm{~g}$ versus média \pm desviopadrão de $9,6 \mathrm{~g} \pm 2,5 \mathrm{~g}$ nos outros cinco galos da categoria leve. Testículos com menos de $3 \mathrm{~g}$ foram encontrados em galos com peso corporal de até $5,20 \mathrm{~kg}$, em $14,8 \%$ dos galos da categoria leve e em $6,8 \%$ dos galos da categoria médio. Hocking (1990) observou atrofia testicular em sete galos Cobb 500 com 60 semanas de idade, que tiveram ganho de peso inferior $600 \mathrm{~g}$ no período de 20 a 60 semanas de idade, sendo que o peso corporal às 20 semanas foi de aproximadamente $2,90 \mathrm{~kg}$. Sexton et al. (1989) mostraram que galos Ross submetidos à restrição alimentar energética severa, com peso corporal 
próximo de $3,50 \mathrm{~kg}$ às 28 semanas de idade e peso corporal inferior a $4,00 \mathrm{~kg}$ às 52 semanas (ganho de peso menor que $500 \mathrm{~g}$ ), pararam de ejacular ou ejacularam sêmen com baixa concentração de espermatozoides. Não ocorreu atrofia testicular em galos Marshall M4 e Cobb 500 que ganharam entre 1,00 e $1,50 \mathrm{~kg}$ de peso corporal de 21 a 60 semanas de idade, sendo que o peso corporal às 21 semanas foi de 3,00 ou $3,50 \mathrm{~kg}$ (Hocking e Bernard, 1997).
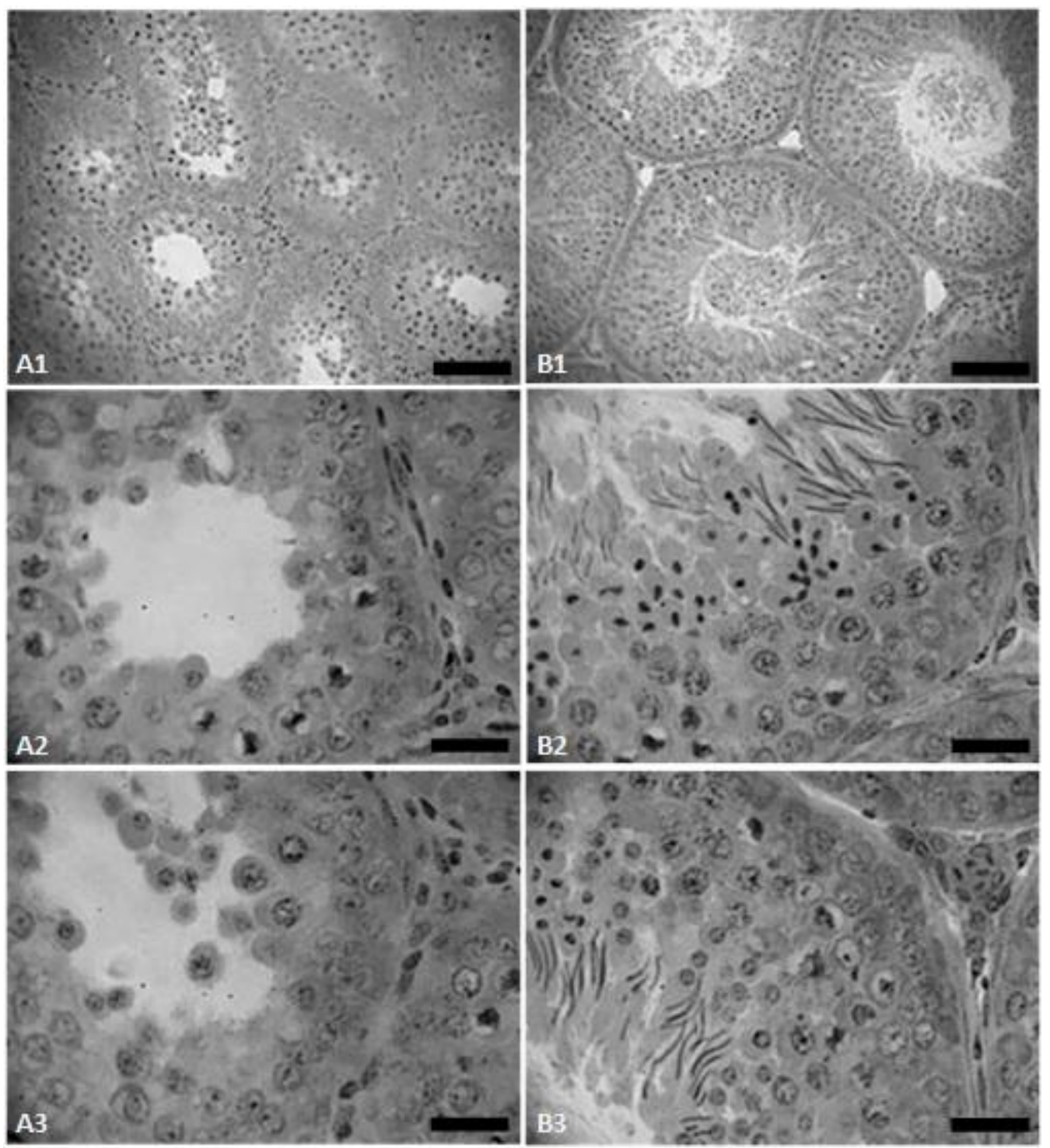

Figura 1. Microscopia de luz do parênquima testicular de galos Cobb 500 Slow com 71 semanas de idade. (A) Galo com atrofia testicular; (B) Galo com espermatogênese aparentemente normal. Barra $=80 \mu \mathrm{m}$

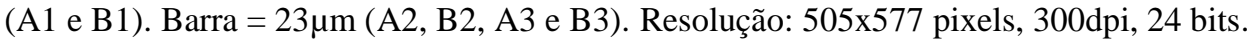

Diferença de até 21,64 vezes foi observada no peso médio dos testículos de galos de mesmo peso corporal. Kirby et al. (1998) observaram diferença maior que 35 vezes no peso médio dos testículos de 103 galos bisavós de linhagens pesadas, não submetidos à restrição alimentar e de mesma idade, o que alerta para a necessidade de se incluírem características reprodutivas na seleção genética de aves de corte (Amann, 1999).

Não houve diferença estatística no diâmetro de túbulo seminífero, na altura de epitélio seminífero, na porcentagem de túbulo seminífero e na porcentagem de tecido intersticial entre os 
galos das categorias leve, médio e pesado (Tab. 4). No galo da categoria leve que apresentou atrofia testicular, estes parâmetros foram de $120,2 \mu \mathrm{m}, \quad 41,1 \mu \mathrm{m}, \quad 86,4 \%$ e $13,6 \%$, respectivamente. Nos outros cinco galos da categoria leve, que apresentaram espermatogênese aparentemente normal, a média \pm desvio-padrão para estes parâmetros foram de $258,9 \pm 42,0 \mu \mathrm{m} ; \quad 80,6 \pm 11,4 \mu \mathrm{m}$; $95,2 \pm 1,1 \%$ e $4,8 \pm 1,1 \%$, respectivamente. Estas médias também não apresentaram diferença estatística quando comparadas às médias das categorias médio e pesado para as mesmas variáveis.

Tabela 4. Parâmetros da histologia do testículo direito de galos Cobb 500 Slow com 71 semanas de idade, em função da categoria de peso corporal

\begin{tabular}{cccccc}
\hline $\begin{array}{c}\text { Categoria de peso } \\
\text { corporal }(\mathrm{PC})\end{array}$ & $\mathrm{n}$ & $\begin{array}{c}\text { Diâmetro de TS } \\
(\mu \mathrm{m})\end{array}$ & $\begin{array}{c}\text { Altura de ES } \\
(\mu \mathrm{m})\end{array}$ & $\% \mathrm{TS}$ & $\% \mathrm{TI}$ \\
\hline $\begin{array}{c}\text { Leve } \\
\text { PC } \leq 4,30 \mathrm{~kg} \\
\quad \text { Médio }\end{array}$ & 6 & $235,8 \pm 68,0 \mathrm{~A}$ & $74,0 \pm 19,1 \mathrm{~A}$ & $93,7 \pm 3,7 \mathrm{~A}$ & $6,3 \pm 3,7 \mathrm{~A}$ \\
$\begin{array}{c}4,30<\mathrm{PC}<5,25 \mathrm{~kg} \\
\quad \text { Pesado }\end{array}$ & 6 & $239,0 \pm 32,2 \mathrm{~A}$ & $77,8 \pm 14,5 \mathrm{~A}$ & $94,0 \pm 1,5 \mathrm{~A}$ & $5,9 \pm 1,5 \mathrm{~A}$ \\
PC $\geq 5,25 \mathrm{~kg}$ & 6 & $251,0 \pm 17,2 \mathrm{~A}$ & $82,0 \pm 6,0 \mathrm{~A}$ & $93,3 \pm 1,5 \mathrm{~A}$ & $6,7 \pm 1,5 \mathrm{~A}$ \\
\hline
\end{tabular}

Resultados apresentados como média \pm desvio-padrão. Médias e desvios seguidos de letras diferentes na mesma coluna diferem pelo teste de Duncan $(\mathrm{P}<0,05) . \mathrm{n}=$ número de repetições. TS = túbulo seminífero. $\mathrm{ES}=$ epitélio seminífero. $\mathrm{TI}=$ Tecido intersticial.

Não foi encontrada correlação significativa entre o peso do testículo direito e a proporção volumétrica de túbulos seminíferos ou de tecido intersticial (Tab. 3). Como mais de $94 \%$ dos galos tiveram espermatogênese aparentemente normal na histologia dos testículos, os resultados mostram que nessas condições a proporção volumétrica dos compartimentos testiculares não varia de acordo com a categoria de peso corporal ou com o peso dos testículos. Apesar de não ter sido observada diferença significativa entre as categorias de peso corporal quanto ao diâmetro de túbulo seminífero e à altura de epitélio seminífero, estes parâmetros apresentaram correlação positiva, moderada e significativa com o peso do testículo direito (Tab. 3).

Não houve diferença significativa no escore de crista entre os galos das categorias pesado e médio, porém estas categorias apresentaram maior escore de crista que os galos da categoria leve $(\mathrm{P} \leq 0,05)$ (Tab. 5). Os galos da categoria pesado apresentaram maior escore de cloaca que os galos da categoria leve $(\mathrm{P} \leq 0,05)$. Não houve diferença estatística significativa no escore de cloaca entre os galos das categorias pesado e médio ou entre os galos das categorias médio e leve (Tab. 5).

Tabela 5. Escores de cloaca e de crista de galos Cobb 500 Slow com 71 semanas de idade, em função da categoria de peso corporal

\begin{tabular}{cccc} 
Categoria de peso corporal $(\mathrm{PC})$ & & Escore de cloaca $(3-8)$ & Escore de crista $(1-4)$ \\
\hline $\begin{array}{c}\text { Leve } \\
\mathrm{PC} \leq 4.300 \mathrm{~kg} \\
\text { Médio }\end{array}$ & $\mathrm{n}=32$ & $5,81 \pm 1,20 \mathrm{~B}$ & $2,38 \pm 0,94 \mathrm{~B}$ \\
$4.300<\mathrm{PC}<5.250 \mathrm{~kg}$ & $\mathrm{n}=60$ & $6,10 \pm 1,07 \mathrm{AB}$ & $3,05 \pm 0,77 \mathrm{~A}$ \\
$\begin{array}{c}\text { Pesado } \\
\mathrm{PC} \geq 5.250 \mathrm{~kg}\end{array}$ & $\mathrm{n}=28$ & $6,39 \pm 0,83 \mathrm{~A}$ & $3,36 \pm 0,68 \mathrm{~A}$ \\
\hline
\end{tabular}

Resultados apresentados como média \pm desvio-padrão. Médias e desvios seguidos de letras diferentes na mesma coluna diferem pelo teste de Kruskal-Wallis $(\mathrm{P} \leq 0,05) . \mathrm{n}=$ número de repetições.

Correlação positiva, moderada e significativa foi encontrada entre o escore de crista e as características peso corporal e peso de testículos (Tab. 3). Tyler e Gous (2009) também encontraram associação positiva e significativa entre o peso médio dos testículos e a área de crista de galos Ross (coeficiente de determinação $\left.\mathrm{r}^{2}=0,69 ; \mathrm{P}<0,001\right)$. A crista é uma característica 
sexual secundária, com desenvolvimento dependente de testosterona (Zeller, 1971). Sexton et al. (1989) mostraram que galos Ross que receberam maiores níveis de energia metabolizável na dieta apresentaram maiores concentrações séricas de testosterona. Possivelmente, galos da categoria pesado são dominantes na competição alimentar e mais eficientes na esteroidogênese. Entretanto, essas características podem não se associar com maior eficiência reprodutiva se o alto peso corporal comprometer a habilidade do galo de completar a cópula (Hocking, 1990).

Correlação positiva, leve e significativa foi encontrada entre o escore de cloaca e as características peso corporal e escore de crista (Tab. 3). Correlação positiva, moderada e significativa foi encontrada entre o escore de cloaca e o peso de testículos (Tab.3). Ao trabalhar com galos de matriz pesada AgRoss 308, Fantini (2007) encontrou correlação positiva, moderada e significativa entre peso corporal e coloração de cloaca (coeficiente de correlação $\mathrm{r}=0,32 ; \mathrm{P}<0,01)$ e observou que galos submetidos a períodos de jejum de cinco e sete dias apresentaram perdas significativas de $13,4 \%$ e $18,2 \%$ do peso corporal, $40,0 \%$ e $44,7 \%$ do peso do testículo esquerdo, $39,8 \%$ e $46,3 \%$ do peso do testículo direito e $6,7 \%$ e $15,6 \%$ do diâmetro de cloaca, respectivamente. Estudos são necessários para avaliar se os parâmetros morfológicos avaliados na determinação do escore de cloaca são testosterona-dependentes ou, em outra hipótese, associam-se com atividade e/ou excitação sexual. A Fig. 2 mostra a morfologia de crista e de cloaca de quatro galos Cobb 500 Slow e suas respectivas classificações em escores.

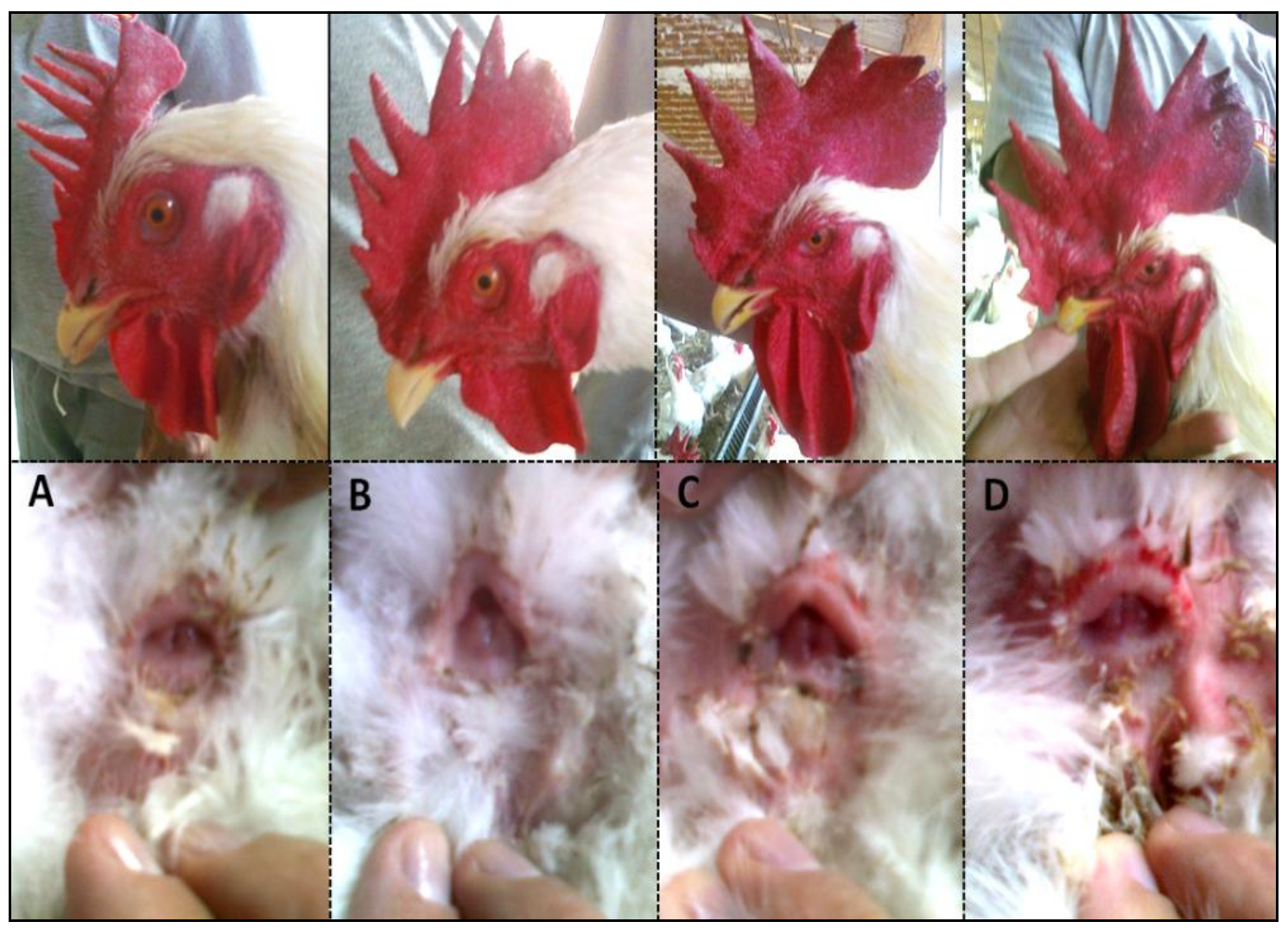

Figura 2. Escores de crista e de cloaca de galos Cobb 500 Slow com 71 semanas de idade. (A) Escore de crista $=1$, crista subdesenvolvida. Escore de cloaca $=5$, cloaca pequena, vermelho-clara e úmida. $(\mathrm{B})$ Escore de crista $=2$, crista média, vermelho- clara e túrgida. Escore de cloaca $=5$, cloaca média, pálida e úmida. (C e D) Escore de crista $=4$, crista muito grande, vermelho- intensa e túrgida. Escore de cloaca = 8, cloaca grande, vermelho-intensa e úmida. Resolução: 1117x706 pixels, 300 dpi, 24 bits. 
Não houve galos com escore de crista " 1 " e/ou escore de cloaca " 3 " ou " 4 " ou galos da categoria leve com escore de crista "2" e escore de cloaca "5" ou "6", com somatório do peso dos testículos maior que 20g (Tab. 6). Hocking (1990) mostrou que em torno de $70 \%$ dos galos Cobb $500 \mathrm{com}$ peso dos testículos $<10 \mathrm{~g}$ e $30 \%$ daqueles com testículos pesando entre 10 e $20 \mathrm{~g}$ têm fertilidade inferior a $25 \%$. Galos com escore de crista " 1 " e/ou escore de cloaca " 3 " ou " 4 " representam
$40 \%$ dos galos com somatório do peso dos testículos menor que $10 \mathrm{~g}$ (Tab.6), sugerindo potencial subfertilidade. Talvez esses galos sejam bons alvos para complementar os descartes quando há intenção de realizar o spiking em lotes com baixa porcentagem de galos com sobrepeso corporal ou com problemas de pés e/ou pernas. Estudos são necessários para verificar esta hipótese.

Tabela 6. Número e porcentagem acumulativa de galos Cobb 500 Slow com 71 semanas de idade, de acordo com o somatório do peso dos testículos $<10 \mathrm{~g}$, entre 10 e $20 \mathrm{~g}$ e $>20 \mathrm{~g}$ e com características de escores de crista e cloaca e de peso corporal (PC)

\begin{tabular}{|c|c|c|c|c|c|c|}
\hline \multirow{2}{*}{ Características } & \multicolumn{3}{|c|}{ Número de galos } & \multicolumn{3}{|c|}{$\%$ acumulativa } \\
\hline & $<10 \mathrm{~g}$ & $10-20 \mathrm{~g}$ & $>20 \mathrm{~g}$ & $<10 \mathrm{~g}$ & $10-20 \mathrm{~g}$ & $>20 \mathrm{~g}$ \\
\hline $\begin{array}{l}\text { Qualquer categoria de peso corporal, } \\
\text { escore de crista "1" e/ou escore de } \\
\text { cloaca " } 3 \text { " ou " } 4 \text { " }\end{array}$ & 4 & 7 & 0 & 40 & 21 & 0 \\
\hline $\begin{array}{l}\text { Categoria leve }(\mathrm{PC} \leq 4.300 \mathrm{~kg}) \text {, escore } \\
\text { de crista " } 2 \text { " e escore de cloaca " } 5 \text { " ou } \\
\text { " } 6 \text { " }\end{array}$ & 1 & 5 & 0 & 50 & 35 & 0 \\
\hline $\begin{array}{l}\text { Categoria médio ou pesado } \\
(\mathrm{PC}>4.300 \mathrm{~kg}) \text {, escore de crista " } 2 \text { " } \mathrm{e} \\
\text { escore de cloaca " } 5 \text { " a " } 8 \text { " }\end{array}$ & 2 & 1 & 5 & 70 & 38 & 15 \\
\hline $\begin{array}{l}\text { Categoria leve }(\mathrm{PC} \leq 4.300 \mathrm{~kg}) \text {, escore } \\
\text { de crista " } 3 \text { " ou " } 4 \text { " e escore de cloaca } \\
\text { " } 5 \text { " a " } 8 \text { " }\end{array}$ & 2 & 4 & 6 & 90 & 50 & 33 \\
\hline $\begin{array}{l}\text { Categoria médio }(4.300<\mathrm{PC}<5.250 \mathrm{~kg}) \text {, } \\
\text { escore de crista " } 3 \text { " ou " } 4 \text { " e escore de } \\
\text { cloaca " } 5 \text { " a "8" }\end{array}$ & 1 & 7 & 8 & 100 & 71 & 58 \\
\hline $\begin{array}{l}\text { Categoria pesado } \quad(\mathrm{PC} \geq 5.250 \mathrm{~kg}) \\
\text { escore de crista " } 3 \text { " ou " } 4 \text { " e escore de } \\
\text { cloaca " } 5 \text { " a "8" }\end{array}$ & 0 & 10 & 14 & 100 & 100 & 100 \\
\hline Número total de galos & 10 & 34 & 33 & & & \\
\hline
\end{tabular}

\section{CONCLUSÕES}

Considerando-se galos Cobb 500 Slow, os resultados mostram que: a) alto peso corporal às 71 semanas de idade tem implicações positivas no peso de testículos e na prevenção de atrofia testicular; b) o peso dos testículos e o peso corporal variam de forma proporcional (IGS não varia entre os galos das categorias de peso corporal leve, médio e pesado); c) em galos com espermatogênese aparentemente normal, não há variação nas porcentagens de túbulos seminíferos e de tecido intersticial, independentemente da categoria de peso corporal e do peso dos testículos; d) o peso do testículo tem associação positiva, moderada e significativa com características histológicas compatíveis com maior capacidade de produção espermática (diâmetro de túbulo seminífero e altura de epitélio seminífero); e) além de maior peso de testículos, galos da categoria pesado apresentam maiores escores de crista e de cloaca que galos da categoria leve; g) escores de cloaca e de crista podem ser utilizados com potencial moderado de predição para identificar galos com baixo peso de testículos. 


\section{AGRADECIMENTOS}

À PifPaf alimentos e aos funcionários da Fazenda Sapezal, em especial ao veterinário Leonardo Eugênio de Araújo Ruiz e ao técnico agrícola Antônio Queiroz Coelho, pela colaboração; à Mara Santos, pelo suporte técnico, à Coordenação de Aperfeiçoamento de Pessoal de Ensino Superior (Capes) e ao Conselho Nacional de Desenvolvimento Científico e Tecnológico $(\mathrm{CNPq})$, pelo suporte financeiro.

\section{REFERÊNCIAS}

AMANN, R.P. Lessons for the poultry industry gleaned from experiences with other commodity species. Poult. Sci., v.78, p.419-427, 1999.

COBB-VANTRESS. Guia de manejo de matrizes, 2008. Disponível em: <http://www.cobb-vantress. com>. Acessado em: $7 \mathrm{dez}, 2012$.

FANTINI, M.O.O. Efeitos da redução do peso corporal sobre as características reprodutivas de galos adultos de matriz pesada. 2007. 42f. Tese (Doutorado) - Escola de Veterinária, Universidade Federal de Minas Gerais, Belo Horizonte.

HOCKING, P.M. The relationships between dietary crude protein, body weight, and fertility in naturally mated broiler breeder males. Br. Poult. Sci., v.31, p.743-757, 1990

HOCKING, P.M.; BERNARD, R. Effects of male body weight, strain and dietary protein content on fertility and musculo-skeletal disease in naturally mated broiler breeder males. Br. Poult. Sci., v.38, p.29-37, 1997.

HOCKING, P.M.; BERNARD, R. Effects of the age of male and female broiler breeders on sexual behavior, fertility and hatchability of eggs. Br. Poult. Sci., v.41, p.370-377, 2000.

KIRBY, J.D.; WASHINGTON, J.; RHOADS, M.L.; KREIDER, D.L. Impaired testis development and spermatogenesis in adult male fowl following unrestricted prepubertal growth and subsequent growth restriction. Poult. Sci., v.77, p.91, 1998.
ROSENSTRAUCH, A.; DEGEN, A.A.; FRIEDLÄNDER, M. Spermatozoa retention by Sertoli cells during the decline in fertility in aging roosters. Biol. Reprod., v.50, p.129-136, 1994.

ROSENSTRAUCH, A.; WEIL, S.; DEGEN, A.A.; FRIEDLÄNDER, M. Leydig cell functional structure and plasma androgen level during the decline in fertility in aging roosters. Gen. Comp. Endocrinol., v.109, p.251-258, 1998.

STATISTICAL Analysis System. SAS INSTITUTE INC. SAS/STAT User's guide. Version 8, Cary, NC: SAS Institute Inc., 1999.

SEXTON, T.J.; RENDEN, J.A.; MARPLE，D.N.; KEMPAINEN, R.J. Effects of dietary energy on semen production, fertility, plasma testosterone, and carcass composition of broiler-breeder males in cages. Poult. Sci., v.68, p.1688-1694, 1989.

TYLER, N.C.; GOUS, R.M. The effect of photoperiod on testis weight and comb area of male broiler breeders. Br. Poult. Sci., v.52, p.517-522, 2009.

USDA (United States Department of Agriculture). Livestock and poultry: world markets and trade, 2012. Disponível em: <http://www.fas.usda.gov/psdonline/ circulars /livestock_poultry.pdf $>$. Acessado em: 3/12/2012.

WEIL, S.; DEGEN, A.A.; ROSENSTRAUCH, A.; FRIEDLÄNDER, M. Intratesticular spermatozoa retention in low fertility aging roosters is related to malformations of SC ectoplasmic specializations. The J. Exp. Zool., v.275, p.317-325, 1996.

WEIL, S.; ROZENBOIM, I.; DEGEN, A.A. et al. Fertility decline in aging roosters is related to increased testicular and plasma levels of estradiol. Gen. Comp. Endocrinol., v.115, p.23-28, 1999.

ZELLER, F.J. The effects of testosterone on dihydrotestosterone on the comb, testis, and pituitary gland of the female fowl. J. Reprod. Fert., v.25, p.125127, 1971 